\title{
ENSAIO SOBRE TEMA DA PRÁTICA DO SERVIÇO SOCIAL NA ÁREA DA
} SAÚDE: A INTERDISCIPLINARIDADE

\section{Danila Carrijo}

Érika Lisboa Porto

Íris Fenner Bertani'.

\section{RESUMO}

A questão da interdisciplinaridade tem sido discutida com intensidade na prática do Serviço Social na área da saúde. Constata-se não só a necessidade da presença de profissionais que atuem no campo da doença em si (médicos, enfermeiros, farmacêuticos), mas de uma equipe composta por profissionais de outras áreas do conhecimento, unindo as ciências humanas às biológicas, no atendimento do indivíduo como um todo. Em relação às questões mais amplas referentes à sociedade em geral, destaca-se a importância do fator político, já que a interligação do conhecimento pode ser a chave para se evitar políticas públicas setorizadas ou setoriais, as quais não alcançam resultados completos, devido ao limite de sua abrangência em relação ao todo. Este estudo sobre a interdisciplinaridade foi direcionado também para análise da fundamentação teórica, destacando alguns obstáculos tais como o positivismo, confusão na conceituação do termo, a própria estrutura das disciplinas e na forma como se desenvolve o trabalho nas instituições, além das diferenças culturais entre diferentes sujeitos e as exigências de individualização e competitividade do mundo atual. Concluímos que na maior parte das vezes o que se observa são momentos interdisciplinares entre áreas afins. Embora cada profissional reconheça a importância da relação com outros profissionais e de um trabalho conjunto, não há por enquanto, manifestações de integração de um plano de tratamento mais voltado às complexas e diferenciadas necessidades do ser humano doente, em detrimento das invisíveis cercas do saber.

PAILAVRAS-CHAVE: Saúde; Serviço Social; Equipe.

\footnotetext{
Universidade Estadual Júlio de Mesquita Filho. Faculdade de Direito. História e Serviço Social - Campus de Franca. Departamento de Serviço Social.

Serviço Social \& Saúde, Campinas, v.2. n.2. p.39-54
} 


\section{INTRODUÇÃO}

Nossa proposta é prestar uma contribuição aos estudos sobre interdisciplinaridade na área da saúde, apresentando uma breve fundamentação teórica sobre o conceito, seus objetivos, a importância da equipe, ressaltando os obstáculos à sua prática e situando esta perspectiva na realidade atual.

A Organização Mundial de Saúde (OMS) define saúde como um estado de completo bem estar físico, mental e social, e não meramente a ausência de doença ou invalidez. A VIII Conferência Nacional de Saúde, em 1986, conceitua saúde a partir do elenco de direitos sociais como alimentação, moradia, emprego e outras (CONFERÊNCIA, 1986). Partindo, portanto, destas afirmações, percebe-se que no caso do Brasil, a maioria da população nunca teve acesso à saúde. Sabe-se que o país possui uma organização social mal estruturada, condições ambientais precárias, ausência de saneamento básico, falta de atendimento médico preventivo, curativo e de reabilitação, entre outras lacunas no atendimento das necessidades humanas básicas (PEREIRA, 2000).

O que por lei é defïnido como direito da população em relação à saúde, na prática não ocorre. Nos grandes hospitais é enorme o número de pessoas que aguardam em filas para receber diversos tipos de tratamento e mesmo nos casos de urgência, muitas vezes, permanecem durante horas nos corredores aguardando por atendimento. Destacamos que o atendimento na área da saúde não se restringe apenas à cura de doenças, pois a pessoa doente pode ser atingida em vários aspectos que abalam suas condições físicas, mentais e sociais.

No decorrer da história da profissão de Serviço Social verifica-se que o Estado é a instituição que mais emprega profïssionais da área. A profisssão vai sofrendo alterações e mudanças em seus objetivos e formas de trabalho, mas sua atuação, conforme o projeto do Estado, focaliza uma atuação de caráter curativo e assistencialista direcionada à saúde coletiva.

Na área da saúde, segundo Minayo (1991), é necessário realizar a crítica à dominação do modelo biomédico tradicional, não de forma reativa, mas numa compreensão integrada, construída como uma proposta articuladora. A separação visível de papéis profissionais nos tratamentos, o trabalho com fragmentos mais ou menos convergentes 
poderia, ao abandonar essa visão do humano, ser melhorado e transformado a partir de uma interligação entre as áreas: o ser humano como ponto de partida e ponto de chegada do conhecimento. Minayo (1991) observa ainda, que nenhuma disciplina por si só dá conta da relação saúde-doença uma vez que ela envolve concomitantes condições sociais, emocionais, afetivas, históricas e biológicas.

O Serviço Social, como profissão de caráter mediador, tem na interdisciplinaridade, determinadas condições epistemológicas como diretrizes básicas. Ou seja, o assistente social faz em sua prática, mediações entre usuário e instituição; usuário e profissionais: entre a realidade das políticas de saúde existentes e as condições estruturais das instituições. e outras.

Esta ampla área de atuação exige do profïssional um conhecimento teórico da doença em si, levando-o a situar-se quanto ao contexto sócio-histórico do tratamento e a necessária interação com a instituição e profissionais de outras áreas.

Verifica-se então, a importância da atuação profïssional voltada a descobrir todas as possibilidades de ação, já que a doença envolve além dos fatores físicos, toda amplitude de questões de âmbito pessoal, familiar e de relacionamento com o meio social. Percebe-se, assim, que o assistente social, bem como os outros profissionais, deve preparar-se para atuar em todas as fases terapêuticas, desde a eventual dificuldade de se anunciar 0 diagnóstico da doença, o acompanhar de todo o tratamento com suas melhorias e recaídas chegando-se à cura, mas também o enfrentamento da doença em sua fase terminal, com situações entre a vida e a morte.

Nesta condição, constata-se não só a necessidade da presença de profissionais que atuem no campo do tratamento em si da doença (médicos, enfermeiros, farmacêuticos), mas de uma equipe composta por profïssionais de outras áreas do conhecimento, ou seja, não só biológicas, mas também humanas, para que seja possível realizar um atendimento que abranja o indivíduo como um todo.

É este o aspecto a que a abordagem interdisciplinar simultânca contribuirá de forma especial, pois é uma prática que favorece a qualidade do atendimento, buscando-se a integração de conhecimentos entre áreas diversificadas do saber. Através dessa perspectiva, torna-se mais clara a posição de que não há área detentora do conhecimento completo, pois todas possuem limitações.

Serviço Social \& Saúde, Campinas, v.2, n.2. p.39-54 
O termo interdisciplinaridade envolve questões amplas dentre as diferentes concepções. Muitas vezes, profissionais afirmam atuar de forma interdisciplinar, no entanto, o que se observa são práticas multidisciplinares. $O$ ato interdisciplinar envolve relaçöes entre a equipe, mais profunda do que simplesmente a presença de vários profissionais de diferentes áreas e o alcance de objetivos comuns. Contudo, é esta última visão que está mais claramente explicitada em grande parte dos centros médicos.

Analisando a realidade destes centros, constata-se que freqüentemente o objetivo profissional comum a todos os envolvidos, é cuidar da pessoa doente. Apesar de respostas alirmativas em relação à existência de um trabalho interdisciplinar, podemos constatar que muitas vezes os profissionais - assistente social, enfermeira, farmacêutica, psicóloga e médico - não atuam enquanto uma equipe. Cada profissional cita a importância da relação com outros profissionais, e embora haja o reconhecimento da possibilidade de um trabalho conjunto, não há por enquanto, manifestações de integração de um plano de tratamento mais voltado às complexas e diferenciadas necessidades do ser humano doente, em detrimento das invisíveis cercas do saber.

O que verificamos é que, na relação profissional existente na área da saúde de um modo geral, o que ocorre são momentos interdisciplinares entre árcas afins.

Os momentos interdisciplinares, como destacamos, podem ser um primeiro passo à instalação da interdisciplinaridade como conduta profissional. Não adianta termos a doce ilusão de dormir sem interdisciplinaridade e acordar com, pois esta resulta de um processo retlexivo e intencional construído gradativamente.

\section{INTERDISCIPLINARIDADE: FUNDAMENTAÇÃO TEÓRICA}

Quando se recorre a certos pensadores, filósofos ou cientistas da história ocidental, constata-se que muitos abordam a questão da unidade do conhecimento humano, ou seja, o conhecimento baseia-se em um mesmo modelo. Há também outros pensadores e fílósofos que acreditam que cada área do conhecimento humano possui um objelo próprio e consequientemente uma metodologia própria, não podendo assim, transferir a metodologia 
de um campo para outro. Nascimento (1995, p. 22) denomina a primeira abordagem citada como "monismo epistemológico" e a segunda como "pluralismo epistemológico".

Em relação ao conhecimento humano, o que deve ser ressaltado é que todas as áreas têm sua importância para a humanidade e nenhuma deve ser destituída de seu lugar. Não há, para Chanlat (1996), território científico isolado que permita interpretar a realidade em sua integralidade, e cada ponto de vista tem uma concepção monocausal.

É preciso buscar a essência de cada um deles, constituindo assim um todo. Para Severino (1995), a questão do uno e múltiplo não é nova, mas o que muda atualmente é o modo de enfocá-la, pois se defende um convívio das mesmas, sem que uma dilua a outra. pois o ser é uno e múltiplo ao mesmo tempo.

Verifica-se que, com o desenvolvimento científico, há uma ampla divisão do saber em especialidades, proporcionando assim, uma fragmentação do conhecimento científico, ou seja, a alienação científica. Esta fragmentação, que ocorre principalmente a partir do século XIX, torna-se perigosa, pois a idéia de conjunto e do todo, acaba sendo ignorada. Percebe-se então, que se torna necessária à busca intencional da unidade. Japiassu afirma que

[...] para além da fragmentação necessáita en que se constituíram as diferentes especialidades. e através das aproximaçōes e das convergências, não devemos renunciar ao esforço de reencontrar a unidade do domínio humano (1976, p. 66).

$O$ assunto interdisciplinaridade vem sendo muito discutido nos últimos anos por diferentes profissionais, dentre eles, os assistentes sociais. Na busca pela unidade, a relação interdisciplinar direciona um trabalho entre disciplinas, com troca de conceitos e experiências, interação e cooperação entre as mesmas.

Cada disciplina proporciona uma visão do real segundo a sua especificidade, o que nos leva a constatar, então, que cada visão é parcial. A interdisciplinaridade proporciona uma reformulação dessa fragmentação, buscando-se uma visão de totalidade do real. Nessa relação interdisciplinar, cada profissional deverá preparar-se para visualizar suas funções, sem negligenciar seu campo de atuação em específico, buscando a visão da unidade através de seus diversos prismas.

Há várias explicações para o termo interdisciplinaridade, o qual é amplo e engloba uma complexidade teórica e prática. Mesmo não sendo possível a exata conceituação, como

Serviço Social \& Saúde. Campinas. v.2, n.2, p.39-54 
afirma Severino (1989), verilicamos que é possível compreendê-la a partir dá explicação de algumas de suas características.

Segundo Japiassu (1976), a característica central da interdisciplinaridade consiste na incorporação dos resultados de várias disciplinas, comparando-as e julgando-as para integrá-las nos conceituais de análise.

A interdisciplinaridade pode ser definida como uma relação de reciprocidade, de mutualidade, que possa pressupor uma atitude diferente de ser assumida; seria substituir a concepção fragmentária pela concepção unitária do ser humano. Caracteriza-se como de natureza não preconceituosa, não desmerecendo assim, diferentes áreas do conhecimento. O saber universal sobrepõe-se ao conhecimento individual.

Pode-se ressaltar mais uma vez a importância, nas relações interdisciplinares, da crítica construtiva, fundamentada na atitude reflexiva sobre a atuação profissional, sempre considerando como meta o alcance dos objetivos em questão. Na integração de posturas diferenciadas, percebe-se a importância da conjunção entre a teoria e a prática, pois é através dela que se consegue a visão do todo. Cada vez mais, com o desenvolvimento das diversas ciências, torna-se necessário um elo de ligação entre as disciplinas, as quais desta forma serão enriquecidas em seus conceitos, metodologias, posturas ideológicas e práticas profissionais.

Um dos objetivos da interdisciplinaridade é encontrar o que existe de comum entre as disciplinas, o que poderá ser alcançado apenas com o confronto dialético entre as mesmas, proporcionando a visão do todo e de suas partes.

É preciso, pois, no dizer de Severino (1989, p. 17), que no âmbito dos esforços com vistas ao conhecimento da realidade humana, se pratique, intencional e sistematicamente, uma dialética entre as partes e o todo, o conhecimento das partes fornecendo elementos para a construção de um sentido total, enquanto o conhecimento da totalidade elucidará o próprio sentido que as partes, autonomamente, poderiam ter. A partir do confronto dialético, percebe-se que as contradições e diferenças existentes entre as disciplinas, proporcionam uma transformação dos profissionais, das ciências e da realidade.

Ressaltamos os aspectos fundamentais de uma prática interdisciplinar, para se alcançar uma visão da sua dimensão: 
[...] aspectos essenciais da prática interdisciplinar: o movimento dialético $[\ldots]$; o exercício da memória $[\ldots]$; a parceria $[\ldots] ;[\ldots]$ a autoridade conquistada e não outorgada; o respeito ao modo de ser de cada um. fazem concluir que a interdisciplinaridade decorre mais do encontro entre indivíduos do que entre disciplinas; a presenca de projetos pessoais de vida unindo o grupo, a contaminação desses projetos, o entusiasmo que suscita desejo de participação (ANDRAUS, 1996, p. 98).

\section{OBSTÁCULOS À INTERDISCIPLINARIDADE}

Na contemporaneidade, o positivismo é considerado um dos maiores obstáculos à interdisciplinaridade, e um dos principais responsáveis pela fragmentação do saber. Ele propõe a ampliação das especialidades, não colocando a importância da interligação dessas disciplinas, ampliando a desarticulação entre as mesmas.

Atualmente, há inúmeras dificuldades para se alcançar a prática interdisciplinar. Quando analisamos a configuração da divisão sócio-técnica do trabalho e da constituição dos saberes, percebemos que cada profissão se insere no mercado de trabalho de forma gradativa, buscando conquistar seu espaço, havendo muitas vezes, competições entre diferentes áreas.

Assim, a proposta de interdisciplinaridade convive na prática com uma "sombra" espessa de um conjunto de estratégias de saber/poder, de competição intra e intercorporativa e de processos institucionais e sócio-culturais muito fortes, que impõem barreiras profundas à troca de saberes e a práticas interprofissionais colaborativas e flexíveis (VASCONCELOS, 1997, p. 146).

Considerando, o que de fato a proposta interdisciplinar busca, perceberemos que ela não procura eliminar as especialidades, nem mesmo o saber individual; ela busca a unidade, a interação e a troca de idéias e práticas.

[...] Já se esclarece um pouco mais o que vem a ser a unidade no interdisciplinar: o que se husca é a substituiçãa de uma Ciência fragmentada por uma Ciência unificada, ou melhor, pleteia-se por uma concepção unitária contra uma concepção fragmentária do Saber científico, o que repercutirá de igual modo nas concepções de ensino, da pesquisa e da extensão (SEVERINO, 1989, p. 15).

Outro obstáculo observado é a própria conceituação da interdisciplinaridade, a qual posiciona-se entre outros termos, como: disciplinaridade, multidisciplinaridade, pluridisciplinaridade e transdiciplinaridade. De acordo com Japiassu (1976). pode-se analisar a diferenciação entre os conceitos citados, como vemos a seguir:

Serviço Social \& Saúde. Campinas, v.2. 1..2. p.39-54 
Disciplinaridade: “[...] Exploração científica especializada de determinado domínio homogêneo de estudo, isto é, o conjunto sistemático e organizado de conhecimentos que apresentam características próprias nos planos do ensino, da formação, dos métodos e das matérias" (JAPIASSU, 1976, p.72).

Multidisciplinaridade: implica em trabalho entre um conjunto de profissionais, no qual há uma justaposição de várias disciplinas, não necessariamente havendo uma coordenação entre os mesmos. Uma disciplina empresta para a outra os seus conhecimentos, sendo assim não ocorre um real enriquecimento nesta relação.

Pluridisciplinaridade; pode ser definido como um sistema que possui um único nível e com objetivos múltiplos, sendo que há presença de diversas disciplinas e cooperação entre as mesmas, mas não há coordenação.

Transdisciplinaridade: apresenta-se como um sistema que possui níveis e objetivos múltiplos. Ocorre a coordenação entre todas as disciplinas e interdisciplinas do campo envolvido, sobre uma base evidente e compartilhada. Possui níveis e objetivos múltiplos. Interdisciplinaridade auxiliar: neste sistema ocorre a utilização de contribuições de uma ou mais disciplinas com o intento de dominar uma disciplina específica que já exista, a qual possui a função de campo receptor e coordenador dos demais. Há a presença de dois níveis, coordenação e objetivos hegemonizados pela disciplina encampadora

Interdisciplinaridade axiomática: sistema comum a um grupo de disciplinas ligadas, cuja definição ocorre em nível hierárquico superior, que introduz a noção de finalidade possuindo certa tendência para a criação de um campo de saber mais autônomo. Neste sistema existem dois níveis e os objetivos são múltiplos, há coordenação que procede de um nível superior e certa tendência a horizontalização das relações de poder.

O diálogo é um dos aspectos da maior importância para uma relação interdisciplinar, mas pode tornar-se um obstáculo à mesma, pois cada disciplina possui Serviço Social \& Saúde, Campinas, v.2, n.2, p. $39-54$ 
linguagem específica. Deve ser realizado um trabalho no qual seja possível troca e discussão de opiniões, de forma clara, havendo uma real integração das informações.

Japiassu (1976, p. 92) esclarece que “[...] a aproximação deve implicar um confronto dos pontos de vista para que as diversas interpretações possam interpenetrar-se com vistas a uma melhor compreensão do objeto a ser estudado".

Mas as disciplinas, preservando suas particularidades e especificidades, dificultam uma verdadeira relação interdisciplinar, sendo necessária à colaboração entre os profissionais, respeitando-se os limites. "Assim, cativado pelo detalhe, o especialista perde o sentido do conjunto, não sabendo mais se situar em relação a ele" (JAPIASSU, 1976, p. 94).

As disciplinas e toda a estrutura existente em cada uma delas, tornam-se muitas vezes, obstáculos à interdisciplinaridade, em alguns aspectos, tais como:

- Cada disciplina possui especialistas, e estes defendem sua especialidade, para que não percam seus espaços profissionais, pois na realidade do mundo atual, a competição amplia-se cada vez mais, impedindo real interação com outras áreas do saber.

- $\quad$ As próprias instituições de ensino, com suas metodologias, muitas vezes já preparam os profissionais com uma formação direcionada à fragmentação do saber e uma valorização total à especificidade de sua especialidade.

- As diferenças culturais existentes entre as disciplinas, implicam em outros fatores importantes, que são as tradições, o prestígio e particularidades de cada uma.

\section{AS CIÊNCIAS E A INTERDISCIPLINARIDADE}

A ciência é caracterizada por uma lógica formal, a qual destaca um saber especializado e vertical, e segundo Demo (1997), ressaltam-se e propagam-se as especializações.

O fator positivo da ampliação e desenvolvimento das especialidades, é que estas avançam em profundidade e extensão seus conhecimentos e pesquisas. Mas é preciso destacar a necessidade de se superar a especialização excessiva, buscando-se a integração de conhecimentos, pois só assim é possível a visão da totalidade do real.

Serviço Social \& Saúde. Campinas. v. 2, n.2. p.39-54 
Quer dizer, em termos concretos: não escapamos de ser especialistas, em nome do conhecimento aprofundado, analiticamente capaz; mas precisamos de especialistas que componham grupos diversificados, ou seja, que saibam dialogar com companheiros especialistas (DEMO,
1997, p. 86).

Para que o diálogo realmente aconteça entre os profissionais de uma equipe, é necessário direcionamento para trocas de idéias comuns ou divergentes. Como resultado desse diálogo verdadeiramente interdisciplinar, temos um enriquecimento tanto dos profissionais em particular, quanto da equipe profissional.

Demo (1997, p. 88), ainda a respeito da complexidade do assunto, faz a seguinte colocação:

Pode-se definir a interdisciplinaridade como a arte do aprofundamento com sentido de abrangência, para dar conta, ao mesmo tempo, da particularidade e da complexidade do real. Precisamente porque este intento é complexo, a interdisciplinaridade leva a reconhecer que é melhor praticada em grupo, somando qualitativamente as especialidades.

Para que esta proposta ocorra, é necessário que os profissionais envolvidos tenham o objetivo de aprender e ensinar conhecimentos, pensar e agir sobre a problemática do trabalho em questão. Na relação interdisciplinar, a práxis é vetor fundamental, pois, a partir da teoria que se estrutura a formação profïssional, juntamente com as trocas de conhecimentos com outros profissionais, havendo uma melhor atuação na prática profïssional para a resolução das problemáticas em questão.

\section{EQUIPE INTERDISCIPLINAR}

Existem algumas distorções quanto a definições do trabalho interdisciplinar e do trabalho em grupo. Muitos confundem estes tipos de trabalho, mas destacamos que não é possível considerar qualquer tipo de grupo de profissionais de diferentes áreas como equipe interdisciplinar. Na equipe interdisciplinar há a participação de profissionais de disciplinas diversificadas, não sendo importante a quantidade de membros, mas o nível de intensidade de integração e interação entre os mesmos. "Assim, não é número maior de pessoas no grupo que traz a interdisciplinaridade, mas sua formação diversificada" (DEMO, 1997, p. $111)$. 
Percebemos que a atitude interdisciplinar engloba atitudes de construções gradativas no decorrer da prática profissional, sendo que não há uma "receita" pronta de como ser um profissional interdisciplinar. Cada um deve buscar juntamente com seu grupo de trabalho uma atuação cooperativa e de respeito mútuo almejando atingir o que fora definido e que possa trazer os melhores resultados. Para haver a verdadeira relação de troca interdisciplinar, é necessário que os profissionais tenham conhecimento do trabalho, de sua especificidade, e que estejam abertos a um processo de interação de seus conhecimentos com profissionais de outras áreas. Não se pode dizer que esta relação seja fácil, pois necessita de total desprendimento de todos os envolvidos, e que os mesmos exteriorizem o que sabem, e interiorizem as informações que recebem, para que em conjunto, consigam a visão de totalidade da situação, dos sujeitos e dos objetos em questão. Para o início do trabalho em equipe interdisciplinar, importa que cada disciplina tenha seu espaço particular de atuação, mas é necessário o respeito pelo saber do outro, para que se alcance um consenso de opiniões. O destaque ao consenso de opiniões ocorte devido às diferenças existentes entre os membros da equipe, pois cada profissional possui sua história de vida, opiniões, formação educacional, cultura e costumes. Todos estes aspectos devem ser considerados, para se entender as dificuldades para a realização efetiva do trabalho interdisciplinar.

As dificuldades enfrentadas pelos profissionais podem ser oriundas da sua formação educacional, que na nossa sociedade freqüentemente é estimulada em direção à individualidade, à competição. É quando verificamos que o processo educativo tem papel fundamental nas barreiras ao alcance da interdisciplinaridade.

Há considerações errôneas sobre o trabalho interdisciplinar, como por exemplo, as colocações que consideram este tipo de trabalho, como uma oportunidade de "comodidade" para os profissionais. O desempenho conjunto de vários profissionais poderá resultar em menos trabalho a ser realizado em particular, por cada membro. Mas sabemos que, se a interdisciplinaridade for realmente interesse do grupo, no lugar da simples intensificação de atividades, haverá o aprofundamento no conhecimento de outras disciplinas, ao mesmo tempo em que, ao colocar sua especificidade, cada um ensina aos outros suas próprias colocações profissionais. "A riqueza do grupo, assim, advém de duas coisas essenciais: da 
competência especializada de cada um, e da capacidade de aprenderem juntos" (DEMO, 1997, p. 120).

Trata-se de uma falácia, dizer ainda que o trabalho em grupo interdisciplinar diminui a responsabilidade individual de cada profissional: na prática, observa-se que esta situação não ocorre, havendo uma "cobrança mútua" entre os próprios membros da equipe em função da qualidade do trabalho.

\section{INTERDISCIPLINARIDADE E A ATUALIDADE}

$\mathrm{Na}$ atual situação em que se encontra o mundo, verifica-se uma globalização de interesses, com uma complexidade de informações que surgem com uma velocidade cada vez maior, de diversas áreas. Contudo, a amplitude de informações, em uma rede complexa de conhecimentos, não leva necessariamente à interdisciplinaridade, pois a complexidade não supõe a integração entre as mesmas.

A interdisciplinaridade, utilizada muitas vezes para definir a interação, colaboração, reciprocidade existentes entre as disciplinas ou setores heterogêneos de uma ciência, está ligada a finalidade de corrigir certos erros surgidos a partir da noção fragmentada da realidade.

Ao se considerar que na atualidade há uma busca de resoluções para os problemas que afligem a sociedade, a perspectiva interdisciplinar poderá proporcionar práticas profissionais diferenciadas, que possam auxiliar no combate de alguns desses problemas.

Na contemporaneidade, o trabalho coletivo tem sido utilizado como alternativa em variados campos, em relação a práticas individualizadas, pois o desenvolvimento ocorre de forma rápida e descontrolada. Ao tentar acompanhar este desenvolvimento, o homem se especializa cada vez mais. Verifica-se, então, que para resultados obtidos individualmente, deve haver a interação de outros resultados, alcançando-se assim novas conclusões que ainda são propositivas a novas buscas, novos conhecimentos.

As especializações, ao se ampliarem, provocam a parcialidade nas análises realizadas, fazendo com que haja uma desarticulação entre aspectos importantes. Portanto, os especialistas, cada vez mais, isolam-se em sua esfera de saber, tornando os estudos mais precisos, específicos e rápidos das questões. Em contrapartida, há um desconhecimento em 
relação a posições exteriores, não havendo uma interligação entre diferentes posições profissionais.

Em relação às questões direcionadas à sociedade como um todo, torna-se necessário destacar a importância do fator político. A política influencia diretamente a problemática vivida pela sociedade, o que vem destacar mais uma vez, a importância de um trabalho em que haja interligação do conhecimento. Como exemplo, temos as políticas setorizadas ou setoriais, as quais não alcançam resultados completos, devido ao limite de sua abrangência em relação ao todo. Ao se considerar que na atualidade há crescente interesse da população na busca da resolução das dificuldades que afligem a sociedade, a perspectiva interdisciplinar poderá vir a proporcionar práticas profissionais, que possam auxiliar no combate desses problemas, a partir do compromisso integrado dos profissionais das diversas áreas. É quando o especialista, segundo Japiassu (1976), deve procurar situar-se no contexto da globalização que se amplia cada vez mais, uma vez que o seu saber específico não será suficiente para visualização e atuação no todo social, havendo sempre necessidade da troca de conhecimentos com outras áreas. Se houvesse real integração entre as diferentes ciências, seria possível haver verdadeiras relações interdisciplinares, longe dos comportamentos de dominação entre as ciências, mas pelo contrário, na busca por atitudes mais humanizadas, com o objetivo da unidade de conhecimentos.

A partir da realidade atual, verifica-se a necessidade de profissionais transformadores e integradores, para que seja possível uma melhor análise da complexidade dos movimentos da sociedade em nosso tempo. São profissionais que devem direcionar sua prática de forma reflexiva, aceitando as diferenças existentes em relação ao outro e ter conhecimento da importância da inter-relação.

A exigência de unidade faz parte da própria natureza de nosso conhecimento. Ela está na origem de todo saber, permanecendo imanente a cada una de suas formas, por mais especializada que seja. O conhecimento humano é sintético e global antes de ser analítico e especializado (JAPIASSU, 1976, p. 112).

Serviço Social \& Saúde, Campinas, v.2. 11.2, p. 39-54 


\section{REFLEXÕES FINAIS}

O termo interdisciplinaridade envolve questões amplas dentre as diferentes concepções, o que vem se refletir nas dificuldades de se construir uma proposta desejável para a área da saúde, embora haja, no ver de Minayo (1991), um ilimitado campo de possibilidades a serem exploradas.

Muitas vezes, profissionais afirmam atuar de forma interdisciplinar, no entanto, o que se observa são práticas multidisciplinares. $\mathrm{O}$ ato interdisciplinar envolve relações entre a equipe, relações estas, mais profundas do que simplesmente a presença de vários profissionais de diferentes áreas e o alcance de objetivos comuns. Contudo, é esta última visão que está mais claramente explicitada em grande parte dos centros médicos.

Analisando a realidade destes centros, constata-se que freqüentemente o objetivo profissional comum a todos os envolvidos, é o de cuidar da pessoa doente. Apesar de respostas afïrmativas em relação à existência de um trabalho interdisciplinar, podemos constatar que muitas vezes os profissionais - assistente social, enfermeira, farmacêutica, psicóloga e médico - não atuam enquanto equipe. Muitos profissionais da saúde, quando indagados, citam a importância da relação com outros profissionais. Esse reconhecimento da possibilidade do trabalho conjunto, não se observa ainda, na maioria das vezes, nas manifestações de integração de um plano de tratamento mais voltado às complexas e diferenciadas necessidades do ser humano doente, em detrimento das invisiveis cercas do saber.

O que verificamos é que, na relação profissional existente na área da saúde de um modo geral, o que ocorre são momentos interdisciplinares entre áreas afïns.

Os momentos interdisciplinares, como destacamos, podem ser um primeiro passo à instalação da interdisciplinaridade como conduta profissional de uma nova racionalidade mais humana e mais totalizante (ANDRAUS, 1996). Não adianta termos a doce ilusão de dormir sem interdisciplinaridade e acordar com, pois esta resulta de um processo reflexivo e intencional construído gradativamente.

Sendo assim, concluímos que, a troca de conhecimentos torna possível a ampliação do saber, através da perspectiva interdisciplinar, pois há também uma real interação e integração entre as disciplinas diante de um objetivo comum. 


\section{ABSTRACT}

The issue of professional team work has been widely discussed in the practice of Social Services in the health area. It is proven that there is not only the need for the presence of professionals that specialize in the field of the disease itself (doctors, nurses, pharmacists), but also for a team composed of professionals from other fields of knowledge, uniting the human sciences with the biological sciences in the treatment of the individual as a whole. Regarding the wider questions concerning society in general, the political factors stand out. as this interlinking of knowledge can be a key in avoiding factional public policies, which do not give complete results due to the limitations of their broader outreach in relation to the whole. This study about team work was also directed toward the analysis of the theoretical founding, relating obstacles such as positivism, confusion on the evaluation of the term, the structure of the disciplines themselves and in the way in which work in the institutions is developed, as well as the cultural differences between different subjects and the demands for individualization and competitiveness of today's world. We have concluded that most of the time what is observed is integration moments between willing areas. Although each professional recognizes the importance of the relationship between other professionals and of working closely together, there are currently no manifestations for integrating a treatment plan which is more closely related to the complex and differentiated needs of the ill human being, in detriment to the invisible fences of leaming.

KEY WORDS: Health; Social Work; Team.

\section{REFERÊNCIAS BIBLIOGRÁFICAS}

ANDRAUS, Rosa Cecília. Olhando para o Serviço Social numa perspectiva interdisciplinar. Bauru-SP: Edusc, 1996.

CHANLAT, Jean-François. Por uma antropologia da condição humana nas organizações. In: SETTE TORRES, Ofélia Lana (Org.). O indivíduo na organização: dimensões esquecidas. VOL.I. 3ed. São Paulo: Atlas, 1996.p.21-45.

CONFERÊNCIA NACIONAL DE SAÚDE. 8, Brasília, Ministério da Saúde, 1996.

Serviço Social \& Saúde. Campinas. v.2, n.2, p.39-54 
DEMO, Pedro. Conhecimento Moderno: Sobre ética e intervenção do conhecimento. Petrópolis-RJ: Vozes, 1997.

JAPIASSU, Hilton. Interdisciplinaridade e patologia do saber. Rio de Janeiro: Imago, 1976.

MINAYO, Maria C. S. Interdisciplinaridade: uma questão que atravessa o saber, o poder e o mundo vivido. Medicina, Ribeirão Preto. V. 4, n. 2, p.70-77, abr.juun. 1991

NASCIMENTO, Carlos Arthur Ribeiro do. Monismo e pluralismo epistemológico. In: MARTINELLI, Maria Lúcia; RODRIGUES, Maria Lúcia (Orgs.). O uno e o múltiplo nas relações entre as áreas do saber. São Paulo: Cortez, 1995. p. 22-28.

PEREIRA, Potyara A. P. Necessidades humanas: subsídios à crítica dos mínimos sociais. São Paulo: Cortez, 2000.

SEVERINO, Antonio Joaquim. Subsídios para uma rellexão sobre novos caminhos da interdisciplinaridade. In: MARTINS DE SÁ, Jeanet L. (Org.). Serviço Social e Interdisciplinaridade: dos fundamentos filosóficos à prática interdisciplinar no ensino, pesquisa e: extensão. São Paulo: Cortez, 1989. p. 11-21.

SEVERINO, Antonio Joaquim. O uno e o múltiplo: conhecimento da verdade e exercício do poder. In: MARTINELli, Maria Lúcia; RODRIGUES, Maria Lúcia (orgs.). O uno e o múltiplo nas relações entre as áreas do saber. São Paulo: Cortez, 1995. p.46-54.

VASCONCELOS, Eduardo Mourão. Serviço Social e interdisciplinaridade: o exemplo da saúde mental. Serviço Social \& Sociedade, São Paulo, ano 18, n. 54, p. 132-154, jul 1997.

DEMO, Pedro. Conhecimento Moderno: Sobre ética e intervenção do conhecimento. Petrópolis-RJ: Vozes, 1997. 